\title{
Assessment of the Hypoglycemic Effects of the Aqueous Extracts of Bauhinia forficata in Wistar Rats Fed with a High Fat Diet
}

\author{
Igor F. S. Oliveira ${ }^{1}$, Hellen S. Neves ${ }^{1}$, Myllena F. Franco ${ }^{1}$, Aluana S. Carlos ${ }^{1}$, Simoni M. Medeiros ${ }^{1}$, Adalgiza \\ Mafra Moreno ${ }^{1}$ Andressa Nunes Araújo ${ }^{1} \&$ Vitor Tenório ${ }^{1}$ \\ ${ }^{1}$ College of medicine, Iguacu University (UNIG), Brazil \\ Correspondence: Vitor Tenório, College of medicine, Iguacu University (UNIG), Brazil. Tel: 55-21-971-032-597. \\ E-mail: tenoriorosa@uol.com.br
}

Received: May 10, 2018

Accepted: May 29, 2018

Online Published: June 30, 2018

doi:10.5539/ijb.v10n3p62

URL: https://doi.org/10.5539/ijb.v10n3p62

\begin{abstract}
This study aimed at analyzing both body and glycemic parameters resulting from the administration of high fat diet and Bauhinia forficata aqueous extract (AqE) in rats. Initially, sixty-day-old rats were divided into two groups. Group C was fed with normocaloric diet and group D was fed with a high fat diet composed of $20 \%$ proteins; $48 \%$ carbohydrate, $20 \%$ lipid, $4 \%$ cellulose, $5 \%$ vitamin and mineral salts. On the 120 day-old group D was subdivided with another D + I group, fed a hyperlipid diet plus administration of Bauhinia forficata AqE for gavage. During experimental period, body mass, food intake and glucose were evaluated. The animals were sacrificed at the age of 150 days. Group $\mathrm{D}$, at 120 days, presented higher body mass compared to group $\mathrm{C}$, but there were no changes in dietary intake. The glycaemia of group D increased compared to group C. At 150 days, the D + I group had a decrease in body mass and glycaemia, and group D continued to gain body mass without changing food intake. Therefore, the findings show that the two-month-diet-period increased body weight and blood glucose. AqE of plant $B$. forficata has pharmacological potential in reducing body mass and decreasing in blood glucose concentrations.
\end{abstract}

Keywords: Bauhinia forficata, aqueous extract, high fat diet, diabetes

\section{Introduction}

Type 2 diabetes mellitus (DM) is a chronic metabolic disorder of various known etiologies. One of the DM etiologies, a world's health problem, is the ingestion of high fat diet, raising the risk of morbidity and mortality (Mohammad, 2014). Associated conditions such as increased hyperglycemia, elevated insulin level or alteration insulin action presents disorder of carbohydrate metabolism and may cause insulin resistance and DM (Christian et al., 2013; Marlon, 2013). Medicine has developed several methods treating diseases, many people constantly choose to use natural plants as treatment. In this sense, many plants with antidiabetical potential are used and some papers prove that diabetes mellitus control may bring new therapeutic possibility (Patel et al., 2012; Pinheiro et al., 2017).

Several species of the Bauhinia genus are used as folk medicines worldwide including Africa, Asia, South America and Central America (Trojan-Rodrigues et al., 2012). B. forficata (Figure 1) is the most studied species in folk Brazil (in a medicinal list) because of its wide geographic distribution, low cost and facility to get the samples, and it is known that this plant has an antidiabetical activity (Cunha et al., 2010; Batista et al., 2013). It is popularly known here as "cow paw" due to the bilobulated aspect of its leaves (Cechinel, 2009).

Considering the need to search for new resources for DM treatment, the present study aimed to evaluate the properties of an aqueous extract of B. forficata fresh leaves in Wistar male rats. 


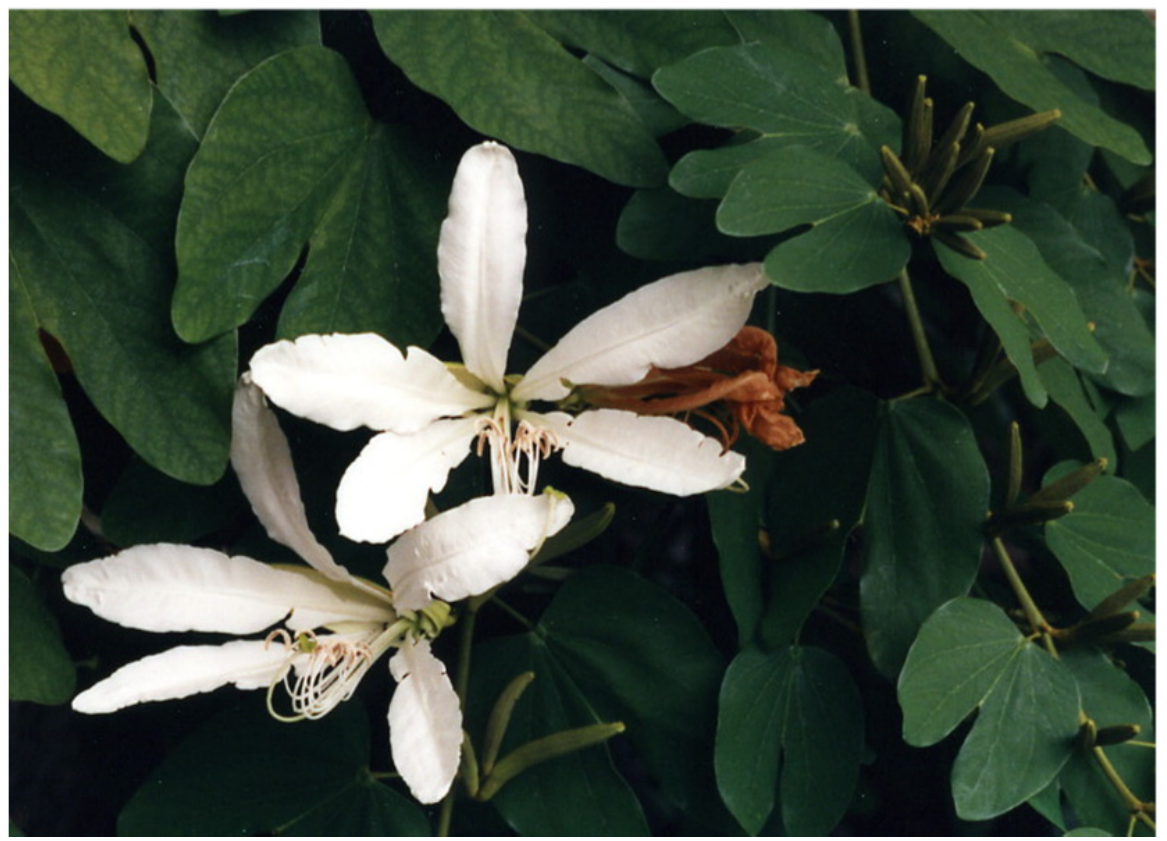

Figure 1. Habitus of $B$. forficata

Note: The representative image of B. forficata commonly known as "Pata de Vaca".

\section{Material and Methods}

\subsection{Botanical Samples}

Plant Specimen and Extraction B. forficata Link leaves were obtained in Nova Iguaçu, Rio de Janeiro, Brazil (-22.9035, -43.2096 (latitude/ longitude)) in March 2016 and were identified by Botanical Ph.D. Vitor Tenório Rosa; a voucher specimen numbered 1052 was deposited in the Universidade Iguaçu ("Iguaçu University") herbarium. The fresh leaves were infused into an extraction (Pepato et al., 2002). In this process, the infusion with the species leaves was performed at a ratio of $150 \mathrm{~g}$ of fresh leaves/liter of water. Subsequently, the extracts were filtered and concentrated under vacuum to obtain the Aqueous Extract (AqE) from B. forficata leaves. The extract was divided into aliquots that were kept in a freezer until the moment of consumption.

\subsection{Biological Material}

This study was carried out in compliance to the ethical principles of experimental animal adopted by Brazilian College of Animal Experimentation (COBEA) and it was approved by Ethic Committee in animals use from Universidade Iguaçu ("Iguaçu University") docketed: PEBIO/UNIG/006/2016.

It was used in male rats of Wistar linage coming from the vivarium colony of the Universidade Iguaçu ("Iguaçu University"). The rats was kept in cages measuring $34 \times 41 \mathrm{~cm}$ with controlled room temperature ( 77 to $\left.80.6^{\circ} \mathrm{F}\right)$, constant humidity and clear/dark cycle of 12 hours (6:00 to 18:00). From 21 day-old on, the animals were fed with regular food (Nuvilab $\left.{ }^{\circledR}\right)$ and filtered water ad libitum.

During all experimental period, animals were weighty and food intake was evaluated. The protocol of offering hight fat and normocaloric diet lasted for two months from 60 day-old. The normocaloric diet consisted in commercial food for rats (Nuvilab®) containing by weight: $19.0 \%$ protein, $56.0 \%$ carbohydrate, $3.5 \%$ lipids, $4.5 \%$ cellulose, $5.0 \%$ of vitamins and minerals, totalizing 17.03kJ/ and high fat (Estadela et al., 2004; Estadela et al., 2011) consisted of a mixture of foods with the following ratio: $15 \mathrm{~g}$ of standard food (Nuvilab $\AA$ ), $10 \mathrm{~g}$ of Roasted peanuts, $10 \mathrm{~g}$ milk chocolate and $5 \mathrm{~g}$ of mastic biscuit. These ingredients were ground, mixed and offered in the form of Pellets, containing by weight: $20 \%$ protein, $48.0 \%$ carbohydrate, $20.0 \%$ lipid, $4.0 \%$ of cellulose, $5.0 \%$ of vitamins and minerals. Energy content of the hyperlipidic diet was here $21.40 \mathrm{~kJ} / \mathrm{g}$. The Experimental groups: (C) rats fed with normocaloric diet; (D): rats fed with high fat diet, (D+I): rats fed with high fat diet plus administration of AqE B. forficata.

The administration to AqE B. forficata was daily at 120 day-old by and was administered via oral gavage. The treatment was performed in the morning at $8: 00$ am with $10 \mathrm{mg} / \mathrm{kg}$ for 30 days. At 150 days-old, the rats were 
sacrificed by exsanguination. The glucose monitoring (60, 90, 120 and 150 day-old) was accomplished by means of blood collection attained from the rats' caudal vein and deposited at glicemic tape which was analyzed with a glucometer ADVANTAGE® (Boehringer Mannheim, USA).

\subsection{Statistical Assessment}

For analysis of food consumption, body mass and glucose levels to the 60 and 120 days it was used the $t$ test of Student not paired. The significance level was set out at $\mathrm{p}<0.05$.

The outcomes of both food consumption and body mass regarding the 150 day-old were analyzed by means of the variance analysis method (ANOVA) bivariate, followed by Bonferroni post test. To further results, the ANOVA univariate method was used, followed by Newman Keuls post test of multiple comparisons. All outcomes were expressed as average \pm standard deviation, considering the significance level of $p<0.05$. The software used was Prism (GraphPad Prism version 6.00 for Windows).

\section{Results and Discussion}

Obesity is a worldwide epidemic causing overconsumption of food, with change in eating patterns and often causing metabolic comorbidities. The increase of blood insulin and glycemic levels are associated to obesity and resistance insulin (Jianping, 2014; Kim et al., 2015).

Our findings showed that high fat diet for 60 calendar days was able to induce obesity. Group D showed significant increase in body mass gain 78 at 120 day-old compare to group C (Fig 2a). The increased energy gain presented is naturally expected from increased fat deposits, especially visceral fat, which is typically proven in resistance insulin and DM (Paniagua, 2016). The D+I group revealed AqE of $B$. forficata gradative normalize body mass (Figure 2b). The literature is controversial regarding acute use of $B$. forficata tea, stating no alterations on the body mass and water intake (Pepato et al., 2002).

The food intake assessment at 60 and 120 (table 1) day-old showed similarities between groups. The D+I (table 1) group showed food intake decrease at 150 with $\mathrm{AqE}$ of B. forficata. According to literature, B. forficata could lead to tissue toxicity by hydrolysable tannins and simple phenols in the leaves (Faria et al., 2004; Salgueiro et al., 2016).

Table 1 . Food intake at 120 and 150 days of life

\begin{tabular}{llll}
\hline Food intake $(\mathrm{g})$ & $\mathrm{C}$ & $\mathrm{D}$ & $\mathrm{D}+\mathrm{I}$ \\
\hline $\mathbf{1 2 0}$ days & $48.00 \pm 1.00$ & $47.33 \pm 1.33$ & $47.70 \pm 1.30$ \\
$\mathbf{1 5 0}$ days & $48.90 \pm 0.50$ & $48.25 \pm 0.19$ & $44.50 \pm 1.25^{*}$ \\
\hline
\end{tabular}

Note. Food intake at 120 and 150 day-old. C (rats fed with normocaloric diet) and Wistar rats, $\mathrm{D}$ (rats fed with high fat diet), $\mathrm{D}+\mathrm{I}$ (rats fed with high fat diet plus administration of AqE B. forficata.). Values represent mean $\pm \mathrm{SEM}$ $* p<0.05$, ANOVA univariate, followed by Bonferroni post test.
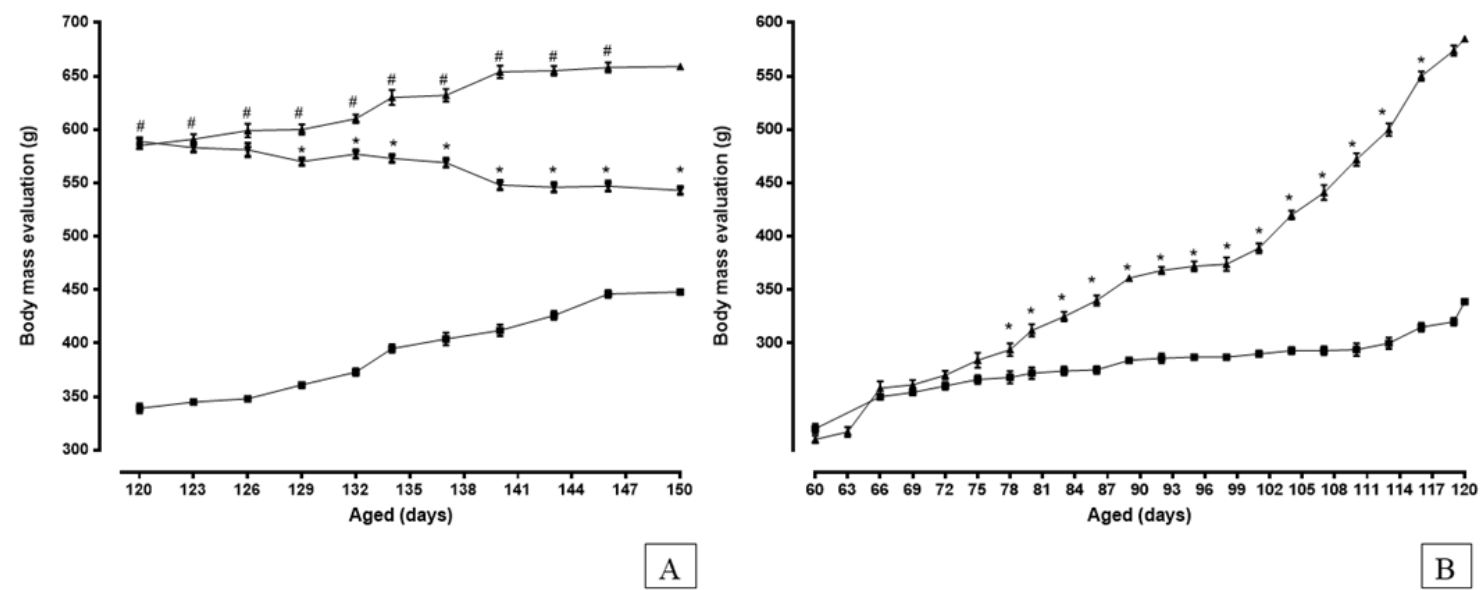

Figure 2. Body mass evaluation

Note. A) 60 at 120 days Wistar rats C (rats fed with normocaloric diet) and wistar rats, D* (rats fed with high fat diet) $\mathrm{T}$ test Student, not paired. B) 120 at 150 days wistar rats, D+I \# (rats fed with high fat diet plus administration of AqE B. forficata.). Values represent mean \pm SEM. ANOVA bivariate, followed post test Bonferroni, $p<0.05$. 
Group D showed higher significant glucose at 120 and 150 days compare to $\mathrm{C}$ and $\mathrm{D}+\mathrm{I}$ groups. These results corroborated with Duarte et al. (2006) who observed the use of high fat and hypercaloric diets unleash the increase on the insulin plasma concentration. Insulin seems to exercise positive feedback on its secretion through the interaction with their receptors in pancreatic beta cells. Desensitization on the action mechanisms of the insulin signaling pathways show correlation between the insulin resistance and the decrease of insulin secretion and these considerations are homologous to the observed in type2-diabetic rats (Fante et al., 2016, Meng et al., 2017).

Group D+I (Figure 3c) that received AqE B. forficata significantly reduced glucose at 150 day-old compared to D group. The hypoglicemic properties of the flavonoids occur in B. forficata (Trojan-Rodrigues et al., 2012). Kaempferol is isolated from $B$. forficata enabling promoting metabolic homeostasis with the improved fasting blood glucose. Reports showed lower glucose level and increase glucose uptake in the rat soleus muscle when isolated from B. forficata. The author suggests that kaempferol stimulates glucose uptake in the rat soleus muscle via the PI3K and PKC pathways and, at least in part, regardless of MEK pathways and the synthesis of new glucose transportes (Zanata et al., 2008).

Future studies need to be accurate so that the results can provide understanding regarding underlying mechanisms.
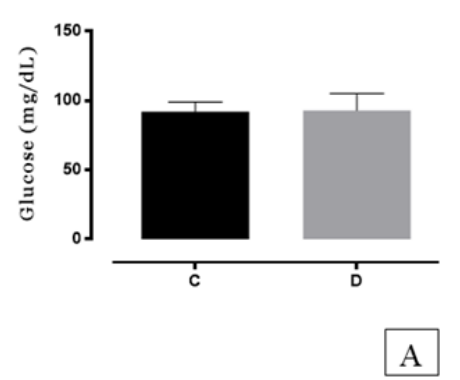
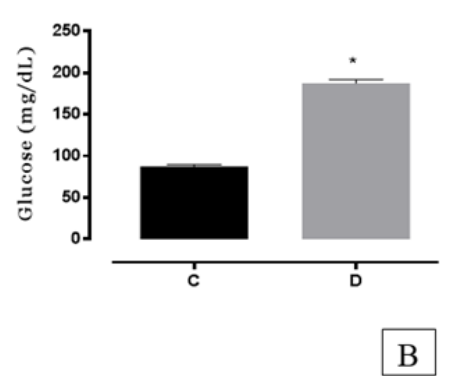
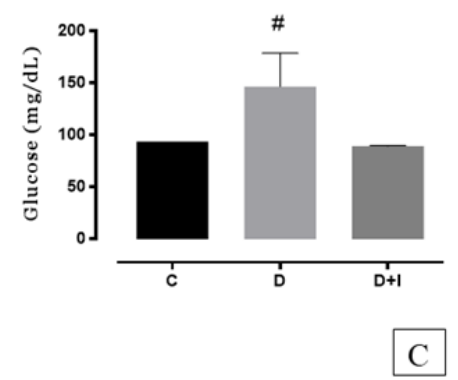

Figure 3. Concentration of blood glucose

Note. a) 60 day-old, b) 120 day-old, c) 150 day-old. C (rats fed with normocaloric diet) and Wistar rats, D (rats fed with high fat diet $\mathrm{D}+\mathrm{I}$ (rats fed with high fat diet plus administration of $\mathrm{AqE}$ B. forficata.). Values represent mean \pm SEM $* p<0.05$, t test of Student, not paired; $\# p<0.05$, ANOVA univariate, followed by Bonferroni post test.

\section{Conclusion}

The experimental high fat diet may represent obesity by its significance on the body mass gain and increased levels of glucose blood in differ times. These observations showed the efficiency of the applied diet here.

The AqE B. forficata was able to decrease blood glucose, body mass and food intake due to its antidiabetic capacity. Moreover, it has been studied and its use is very promising for the design of new pharmaceutical forms. The value of this plant in pharmacological therapy, it is very important to be studied and its use is very promising.

\section{Conflicts of interests}

The authors have declared no conflict of interests.

\section{Acknowledgements}

The authors would like to take the opportunity to thank to the scientific initiation program of Universidade Iguaçu ("Iguaçu University") herein represented by professor Paula Guidone and Gildasio Costa.

\section{References}

Asif, M. (2014). The prevention and control the type-2 diabetes by changing lifestyle and dietary pattern. Journal of education and health promotion, 3. https://dx.doi.org/10.4103\%2F2277-9531.127541

Batista, P. N., Oliveira, T. C., Leal, F. R., Batista, N. A., De Medeiros, M. G. F., \& Nunes, L. C. C. (2013). The influence of using Bauhinia forficata Link in glycemic, lipid and toxicological profile in vivo experimental models: A systematic review. J Med Plant Res., 7(31), 2343-2348. https://doi.org/10.5897/JMPR2013.5107

Cechinel, F. V. (2009). Chemical composition and biological potential of plants from the genus Bauhinia. Phytother Res., 23(10), 1347-54. https://doi.org/10.1002/ptr.2756

Cerf, M. E. (2013). Beta cell dysfunction and insulin resistance. Frontiers in endocrinology, 4, 37. https://dx.doi.org/10.3389\%2Ffendo.2013.00037 
Christian, K. R., Andrea, L. H., \& Barnard, R. J. (2013). Metabolic Syndrome and Insulin Resistance: Underlying Causes and Modification by Exercise Training. Compr Physiol., 3(1), 1-58. https://doi.org/10.1002/cphy. c110062

Cunha, A. M., Menon, S., Menon, R., Couto, A. G., Bürger, C., \& Biavatti, M. W. (2010). Hypoglycemic activity of dried extracts of Bauhinia forficata Link. Phytomedicine, 17, 37-41. https://doi.org/10.1016/j.phymed. 2009.06.007

Estadella, D., Oyama, L. M., Bueno, A. A., Habitante, C. A., Souza, G. I., Ribeiro, E. B., ... \& do Nascimento, C. M. O. (2011). A palatable hyperlipidic diet causes obesity and affects brain glucose metabolism in rats. Lipids in health and disease, 10(1), 168. https://doi.org/10.1186/1476-511X-10-168

Estadella, D., Oyama, L. M., Dâmaso, A. R., Ribeiro, E. B., \& Do Nascimento, C. M. O. (2004). Effect of palatable hyperlipidic diet on lipid metabolism of sedentary and exercised rats. Nutrition, 20(2), 218-224. https://doi.org/10.1016/j.nut.2003.10.008

Faria, R. A., Andrade-Neto, M., Pinto, L. S., Castellon, R. R., Calvete, J. J., \& Cavada, B. S. (2004). Biochemical and chemical partial characterization of Bauhinia forficata Link seeds. Archivos latinoamericanos de nutricion, 54(3), 349-353.

Kim, M. K., Reaven, G. M., Chen, Y. D. I., Kim, E., \& Kim, S. H. (2015). Hyperinsulinemia in individuals with obesity: Role of insulin clearance. Obesity, 23(12), 2430-2434. https://dx.doi.org/10.1002\%2Foby.21256

Paniagua, J. A. (2016). Nutrition, insulin resistance and dysfunctional adipose tissue determine the different components of metabolic syndrome. World journal of diabetes, 7(19), 483-514. https://dx.doi.org/10.4239\%2Fwjd.v7.i19.483

Patel, D. K., Kumar, R., Laloo, D., \& Hemalatha, S. (2012). Diabetes mellitus: an overview on its pharmacological aspects and reported medicinal plants having antidiabetic activity. Asian Pacific Journal of Tropical Biomedicine, 2(5), 411-420. https://doi.org/10.1016/S2221-1691(12)60067-7.

Pepato, M. T., Keller, E. H., Baviera, A. M., Kettelhut, I. C., Vendramini, R. C., \& Brunetti, I. L. (2002). Anti-diabetic activity of Bauhinia forficata decoction in streptozotocin-diabetic rats. Journal of Ethnopharmacology, 81(2), 191-197. https://doi.org/10.1016/S0378-8741(02)00075-2

Pinheiro, M. S., Rodrigues, L. S., S NETO, L. E. I. L. A., Moraes-Souza, R. Q., Soares, T. S., Americo, M. F., ... \& Volpato, G. T. (2017). Effect of Bauhinia holophylla treatment in Streptozotocin-induced diabetic rats. Anais da Academia Brasileira de Ciências, 89(1), 263-272. https://doi.org/10.1590/0001-3765201720160050.

Salgueiro, A. C. F., Folmer, V., da Silva, M. P., Mendez, A. S. L., Zemolin, A. P. P., Posser, T., ... \& Puntel, G. O. (2016). Effects of Bauhinia forficata tea on oxidative stress and liver damage in diabetic mice. Oxidative medicine and cellular longevity, 2016. https://doi.org/10.1155/2016/89029

Trojan-Rodrigues, M., Alves, T. L. S., Soares, G. L. G., \& Ritter, M. R. (2012). Plants used as antidiabetics in popular medicine in Rio Grande do Sul, southern Brazil. Journal of Ethnopharmacology, 139(1), 155-163. https://doi.org/10.1016/j.jep.2011.10.034

Ye, J. P. (2013). Mechanisms of insulin resistance in obesity. Frontiers of medicine, 7(1), 14-24. https://doi.org/10.1007/s11684-013-0262-6

Zanatta, L., Rosso, Â., Folador, P., Figueiredo, M. S., Pizzolatti, M. G., Leite, L. D., \& Silva, F. R. (2008). Insulinomimetic effect of kaempferol 3-neohesperidoside on the rat soleus muscle. Journal of natural products, 71(4), 532-535. https://doi.org/10.1021/np070358

\section{Copyrights}

Copyright for this article is retained by the author(s), with first publication rights granted to the journal.

This is an open-access article distributed under the terms and conditions of the Creative Commons Attribution license (http://creativecommons.org/licenses/by/4.0/). 